\title{
edificio de la dynamit A. G. en Troisdorf
}

PAUL SCHAEFFER, arquitecto B. D. A.

$125-18$
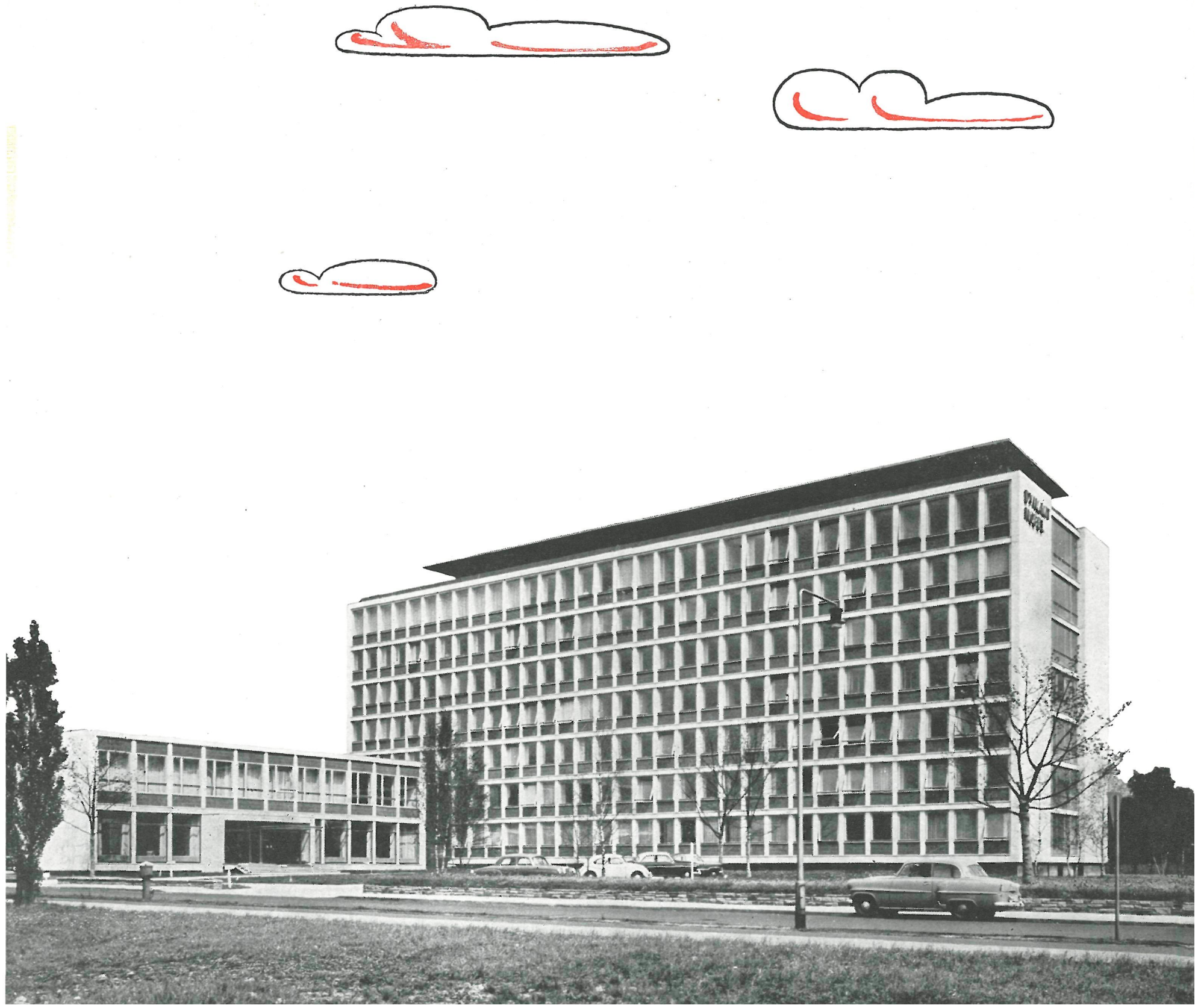


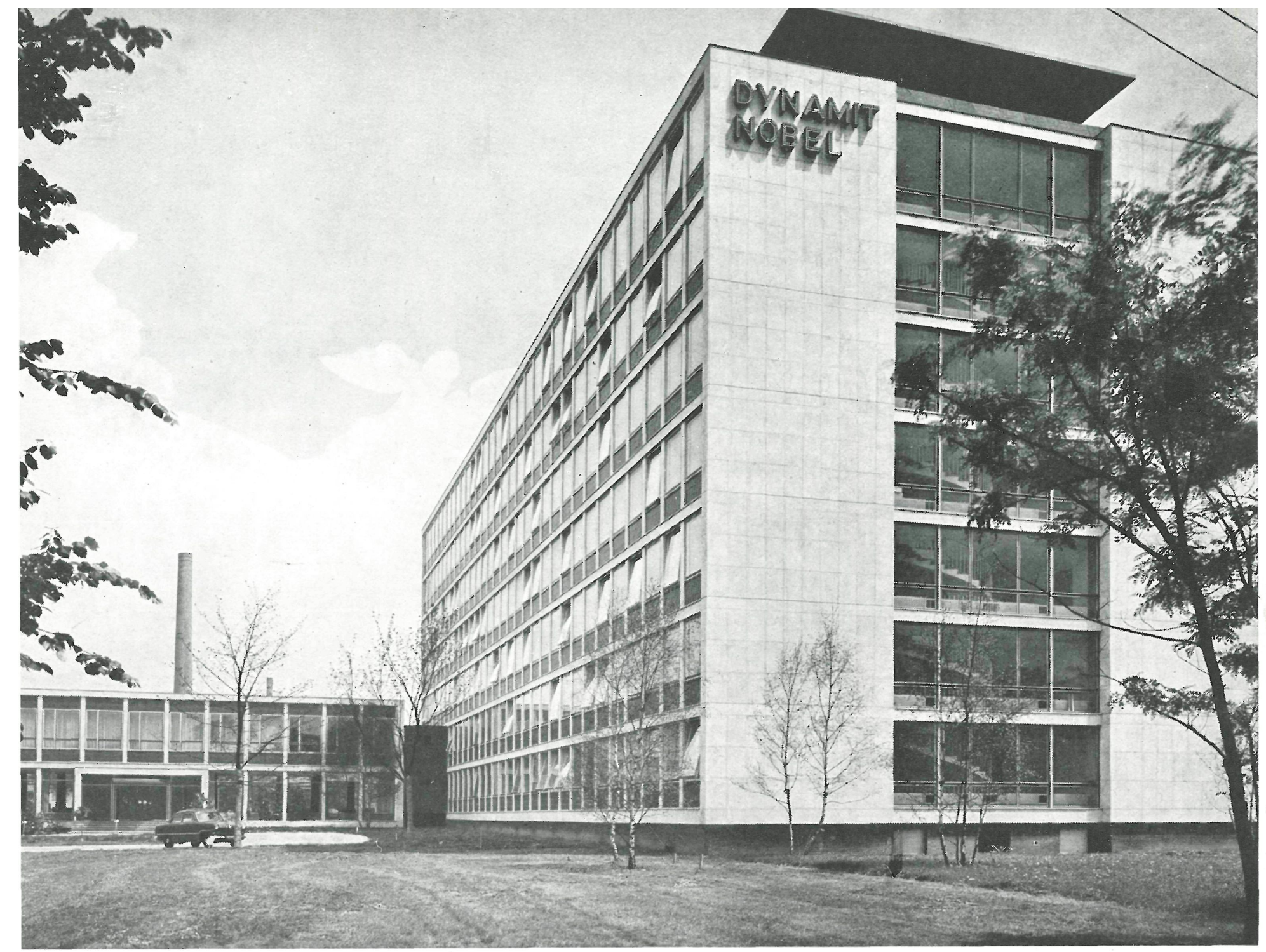

\section{Plano de situación:}

1. Calle Kaiser: entrada principal y acceso a las oficinas.-2. Calle Kölrner, sobre la carretera Siegburgo-Colonia.-3. Nueva construcción de la Dirección General.-4. Ampliación del bloque destinado a la dirección.-5. Parque de aparcamiento para 84 coches.-6. Aparcamiento de bicicletas.-7. Planta baja de tiendas.-8. Laboratorio cientifico.-9. Laboratorio cientifico. 10. Proyecto de futura realización.-11. Dirección de oncinas. Cuatro plantas.-12. Consulta medica . Dos plantas. -13. Consula medica. Planta baja.-14. Nueva casa de guardas. 16 . Itán ya proyectados.

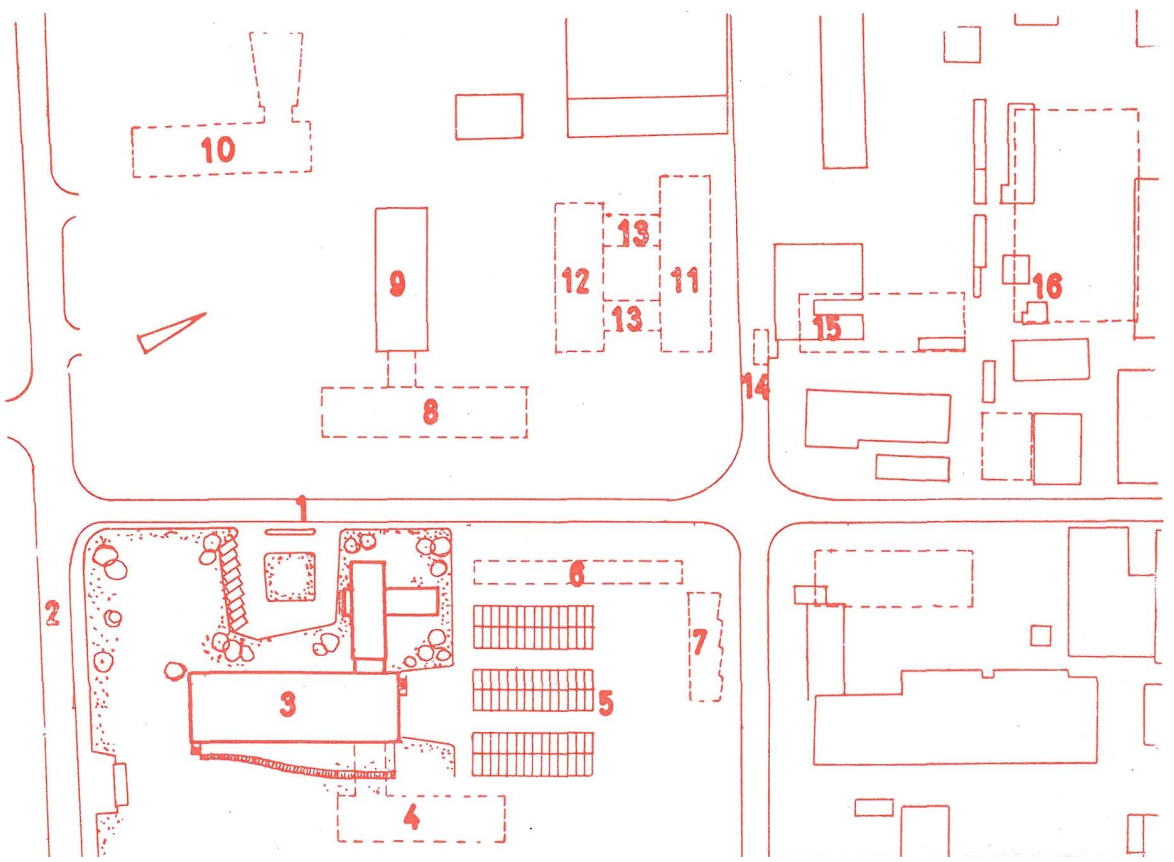

En el cruce de la calle Kölner y la Kaiser se levanta el nuevo edificio de la Dirección General de la "Dynamit" A. G.

La construcción no ocupa más que una parte del terreno; el resto es una pradera de césped y arbolado. Desde estas zonas verdes el visitante puede apreciar el conjunto de los dos bloques construídos. En fecha ulterior se piensa construir en ellas un centro de recreo para los empleados de la firma.

Al planear los accesos y aparcamientos se tuvieron presentes los siguientes puntos:

a) La zona de aparcamiento, dedicada a los empleados, debía situarse en lugar retirado.

b) Era necesario un aparcamiento limitado para uso de los altos jefes y visitantes de importancia. 

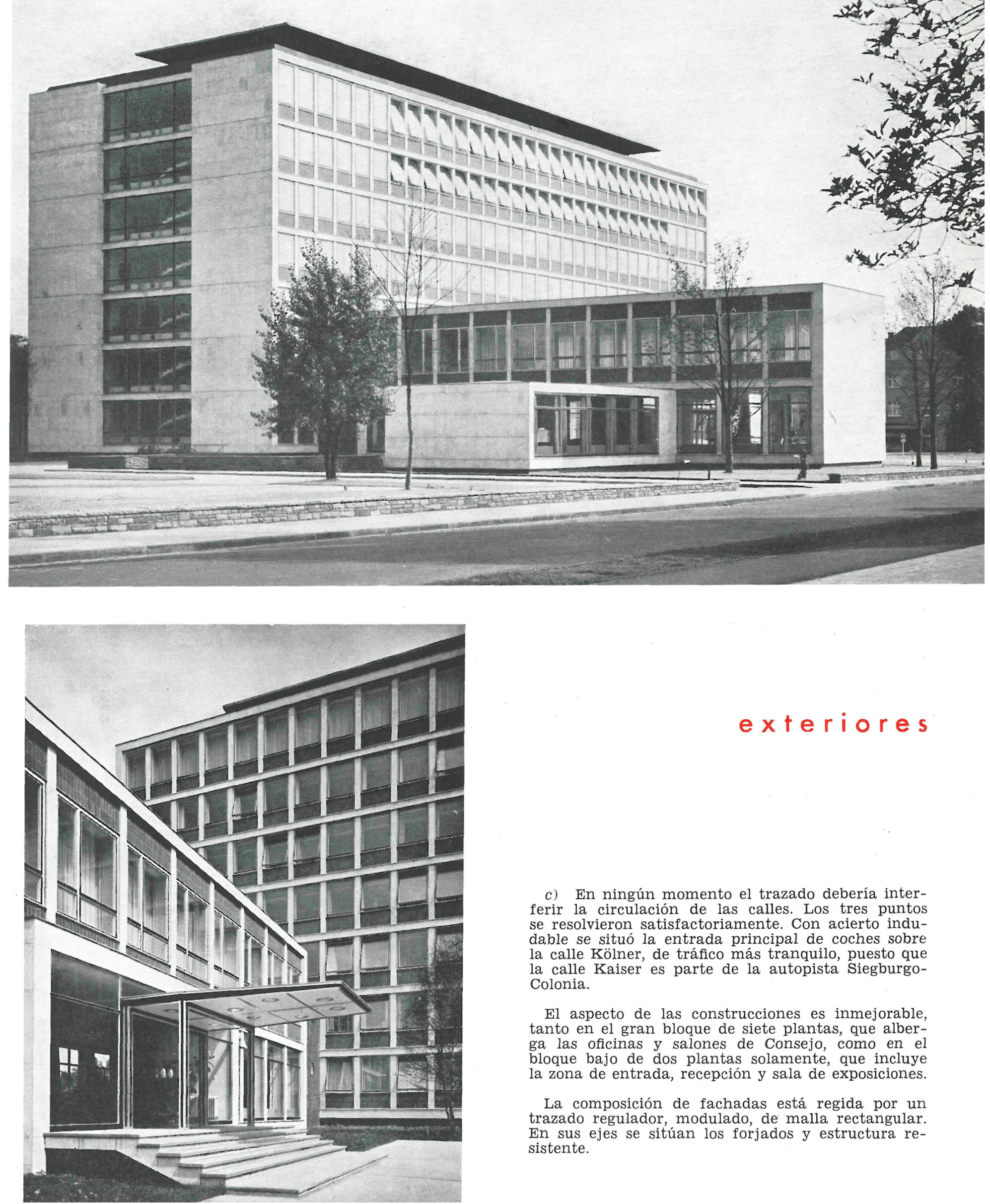

exteriores

c) En ningún momento el trazado debería interferir la circulación de las calles. Los tres puntos se resolvieron satisfactoriamente. Con acierto indudable se situó la entrada principal de coches sobre la calle Kölner, de tráfico más tranquilo, puesto que la calle Kaiser es parte de la autopista SiegburgoColonia.

El aspecto de las construcciones es inmejorable, tanto en el gran bloque de siete plantas, que alberga las oficinas y salones de Consejo, como en el bloque bajo de dos plantas solamente, que incluye la zona de entrada, recepción y sala de exposiciones.

La composición de fachadas está regida por un trazado regulador, modulado, de malla rectangular. En sus ejes se sitúan los forjados y estructura resistente. 

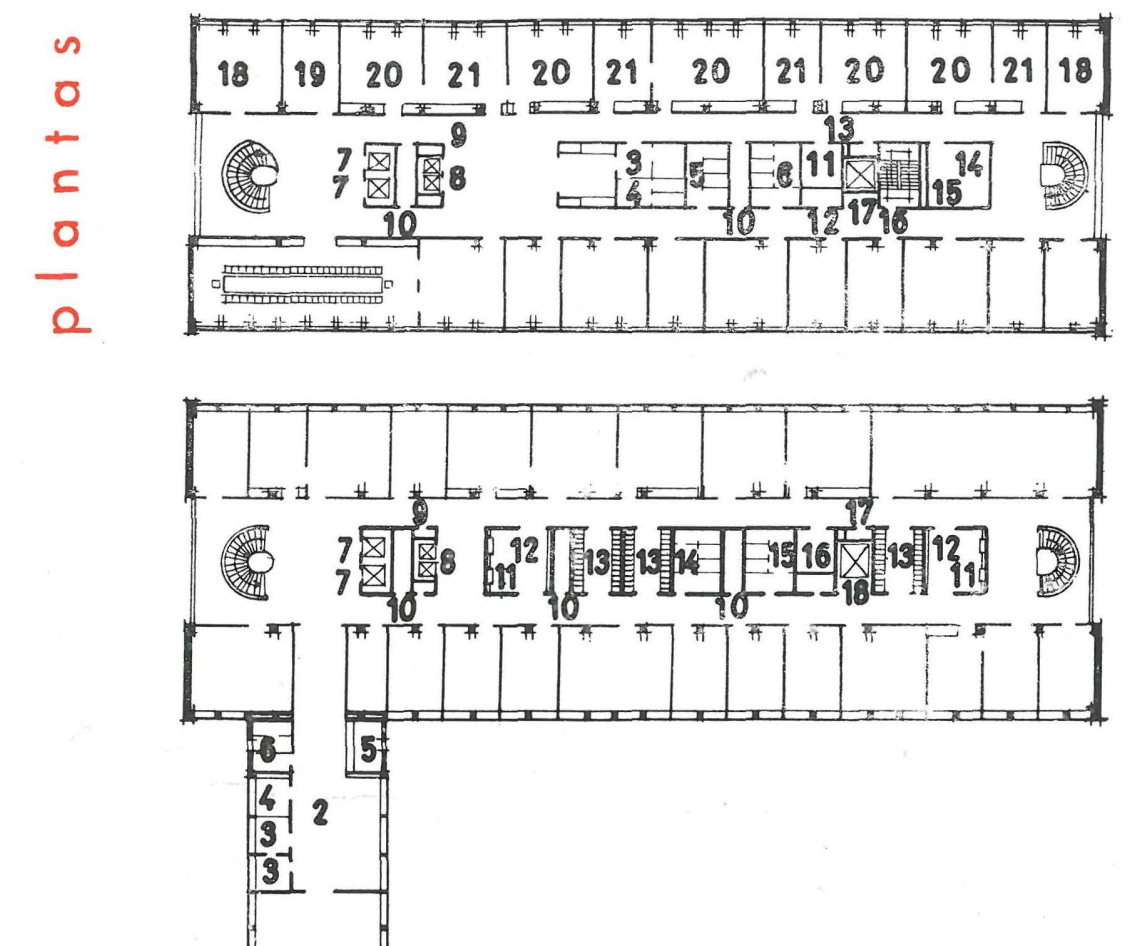

planta primera:

1. Gran salón.-2. Antecámara.-3. Salón de reuniones.-4. Maquinaria de ventilación del gran salón. - 5. Guardarropa. - 6. Aseo caballeros. 7. Ascensores.-8. Paternóster.-9. Extintor de in cendios. - 10. Instalaciones.-11. Sala de reuniones. 12. Ventiladores.-13. Guardarropa.-14. Aseo de 17. Sala de limpiezas.-18. Montacargas $(1.200 \mathrm{~kg})$.

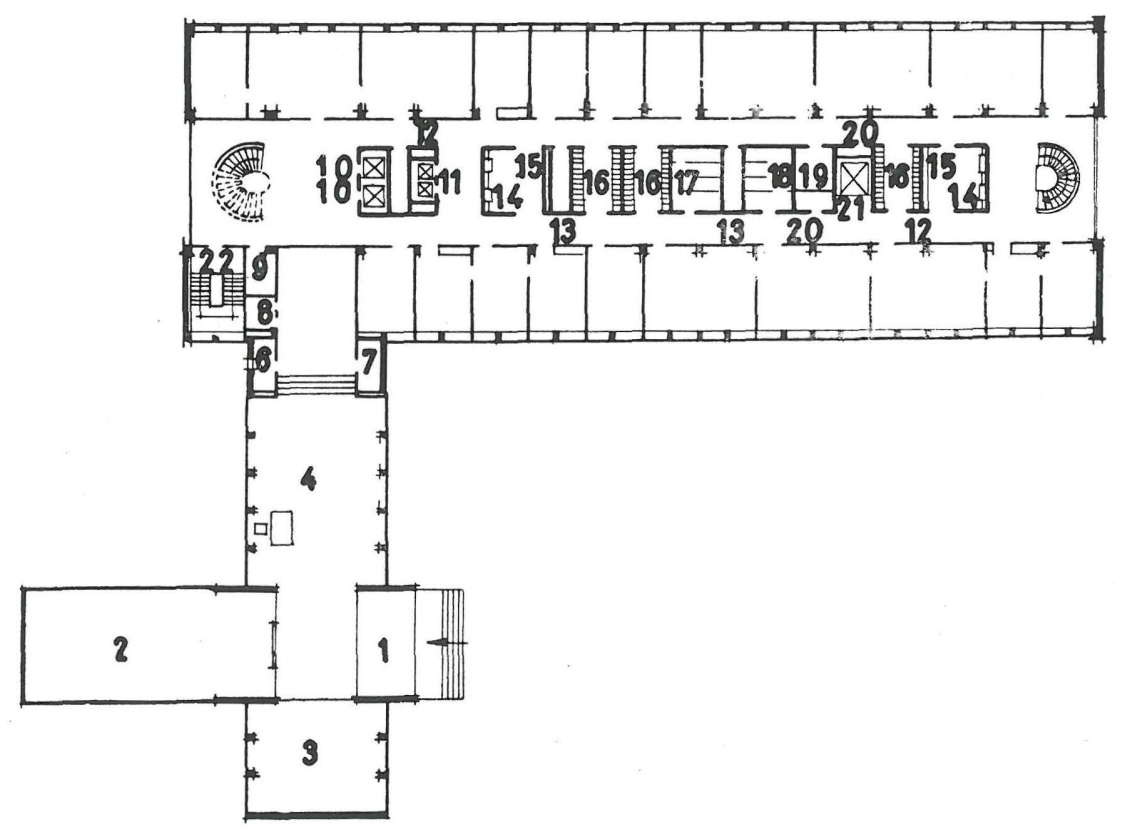

\section{planta baja:}

1. Entrada.-2. Gran salón de exposiciones.-3. Salón de exposiciones.-4. Hall de ingreso.-5. Guarda.-6. Vestuario del guarda.-7. Distribución eléctrica.-8. Cabinas telefónicas.-9. Sala de reuniones.-10. Ocho ascensores.-11. Paternóster.-12 Extintor de incendios.-13. Instalaciones.-14. Locutorio.-15. Ventilación.-16. Guardarropa.17. Aseo señoras.-18. Aseo caballeros.-19. Ordenanza.-20. Cuarto de limpieza.21. Montacargas $(1.200 \mathrm{~kg})$.-22. Escalera hacia el sótano.

\section{planta sexta}

1. Sala de reuniones.-2. Guardarropa para el cuerpo directivo.-3. Baño para el cuerpo directivo.-4. Aseo para el cuerpo directivo - 5. Aseo de señoras - 6 . Aseo de caballeros -7 . Ocho ascensores -8 . Paternóster.-9. Extintor de incendios.-10. Ins talaciones. - 11 Cuarto de ordenanza 12. Cuarto de limpieza-13 Armario. limpieza.-14. Archivos - 15 . Armario de 16. Escalera hacia la planta superior. 17. Ascensor montacargas (1.200 kg). 18. Sala de Consejos - 19

20. Cuerpo directivo-21. Secretarí

Tanto los unos como la otra están revestidos de piedra caliza, cuyo despiece regular, regido por el trazado mencionado anteriormente, queda interrumpido por piezas de menor dimensión correspondientes a las franjas situadas sobre los forjados. Los antepechos de las ventanas se han recubierto con piezas cerámicas vidriadas de color verde. El bloque de oficinas está rematado en terraza cubierta. La marquesina que la cubre tiene su cara inferior pintada en rojo pálido, y bajo ella están alojadas la maquinaria de ascensores y la instalación de aireación del edificio.

Las comunicaciones verticales entre las sucesivas plantas están aseguradas por dos ascensores rápidos, un ascensor paternóster y dos escaleras, muy amplia la principal y otra de servicio. La disposición general de las plantas de oficinas es la siguiente: las dos crujías en fachada, ocupadas por los despachos de trabajo; a lo largo de ellas, dos pasillos aseguran las comunicaciones horizontales, y en sus extremos están situadas las escaleras, tras los muros testeros ampliamente acristalados. Entre estos dos pasillos, una crujía de locales, sin ventilación ni luz naturales, encierra los vestuarios, cuartos de limpieza, archivos, etc. La zona de despachos de la sexta planta está ocupada por las grandes salas de Consejo y Asamblea de la Dirección.

Siempre que fué posible se emplearon productos de la "Dynamit" A. G.: en los pasamanos de las escaleras; en su peldañeado, con cantos reforzados por perfiles de "Mipolan"; en los solados y revestimientos interiores de la mayor parte de las salas; en las cabinas de los ascensores; en los armarios empotrados; en las cortinas y protección de puertas, etc. Los pisos son, en general, de tono uniforme; algunos, sin embargo, presentan dibujos en tonos y colores diferentes, en damero, franjas laterales, etc.

El panel decorativo realizado en el muro posterior de la sala de exposición es ingenuo y alegre, y en él también se emplearon productos de la firma, de colores vivos y gama muy variada. La decoración de interiores es sencilla, de una austera elegancia acogedora y confortable. 


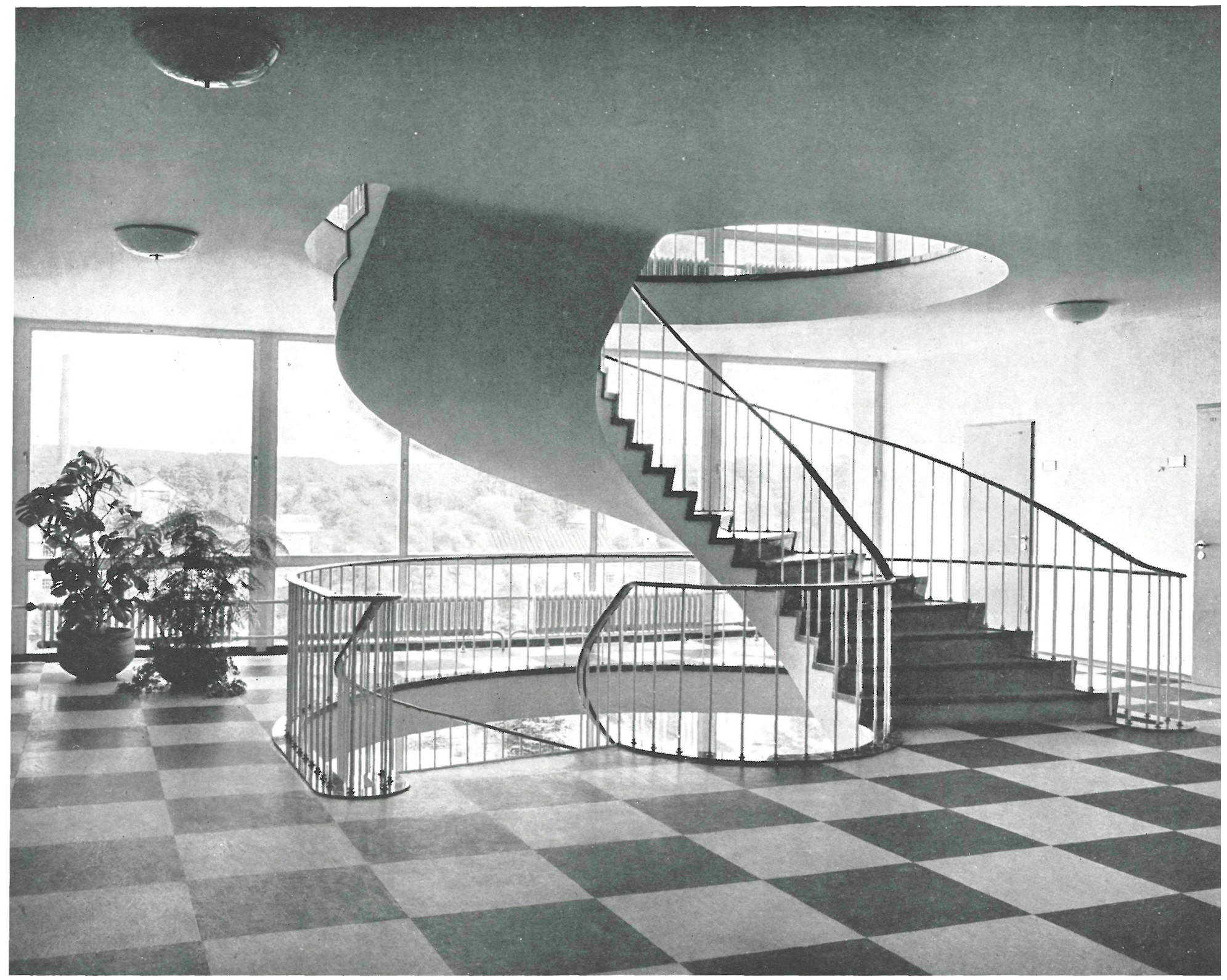

El mobiliario de todo el edificio fué construído y diseñado especialmente para él.

En resumen: el edificio de la nueva Dirección General de la "Dynamit" A. G. es un proyecto que resuelve airosamente los problemas, cubre ampliamente un programa bien definido y es una construcción de sólido aspecto, sin énfasis arquitectónico, en el que todo nace de una unidad de dirección y un acertado criterio. 


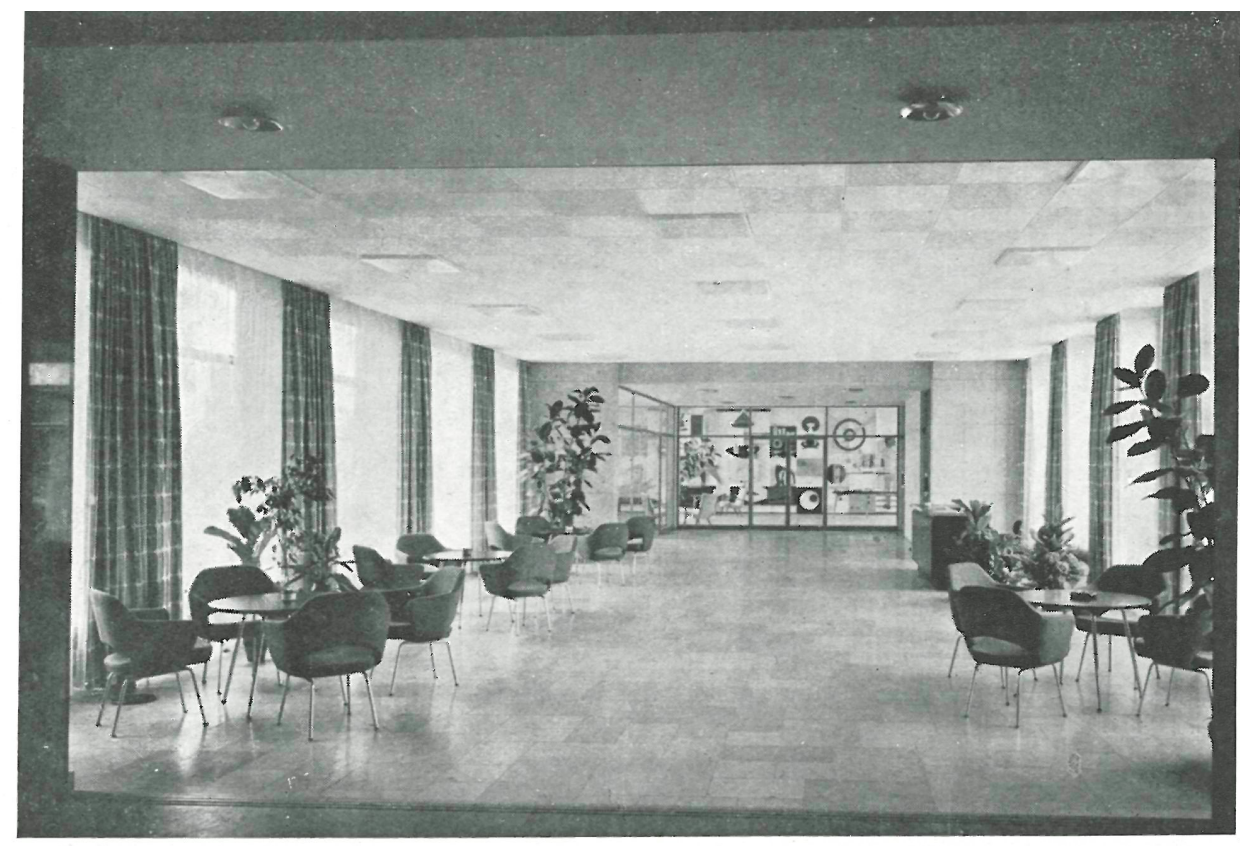

interiores

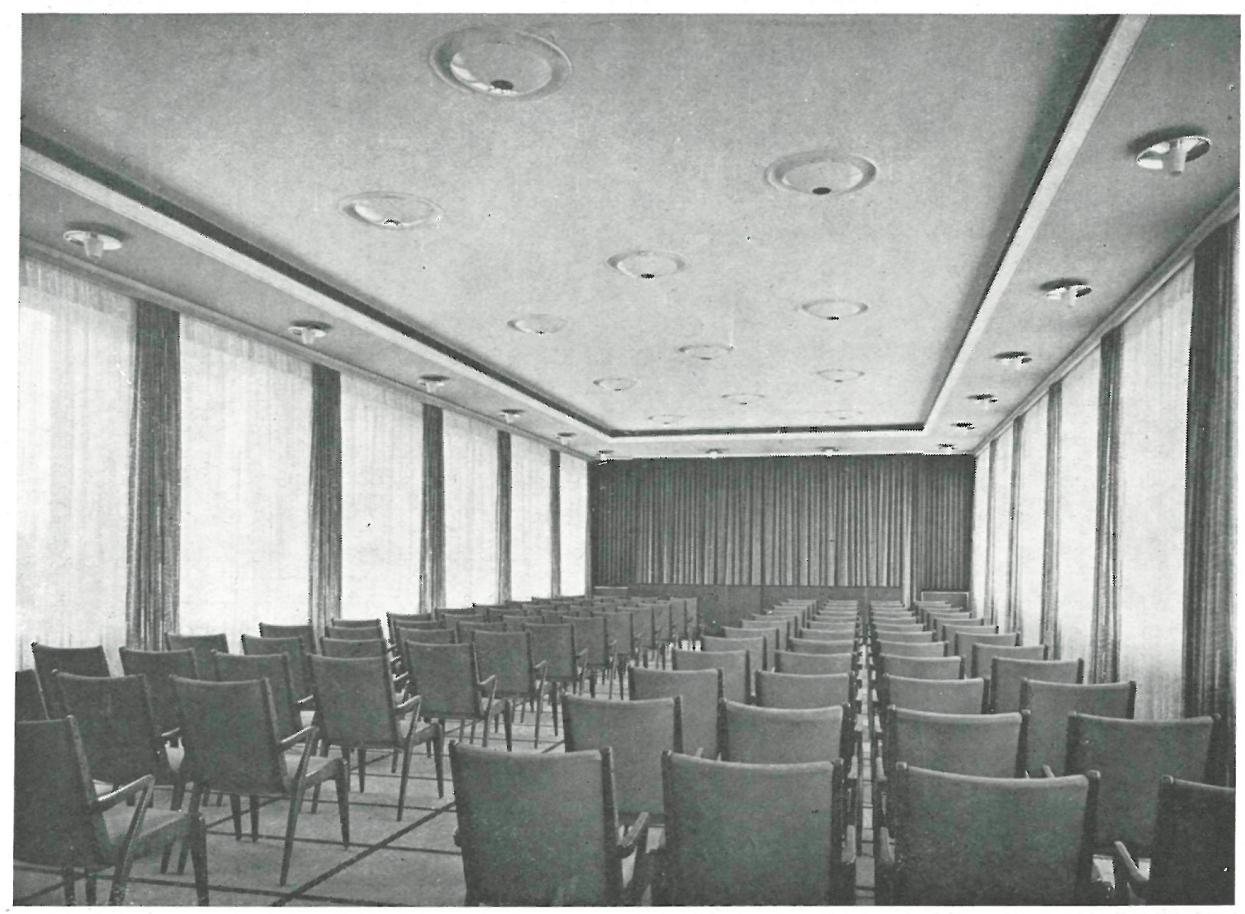

Vestíbulo de entrada.

Sala de conferencias.

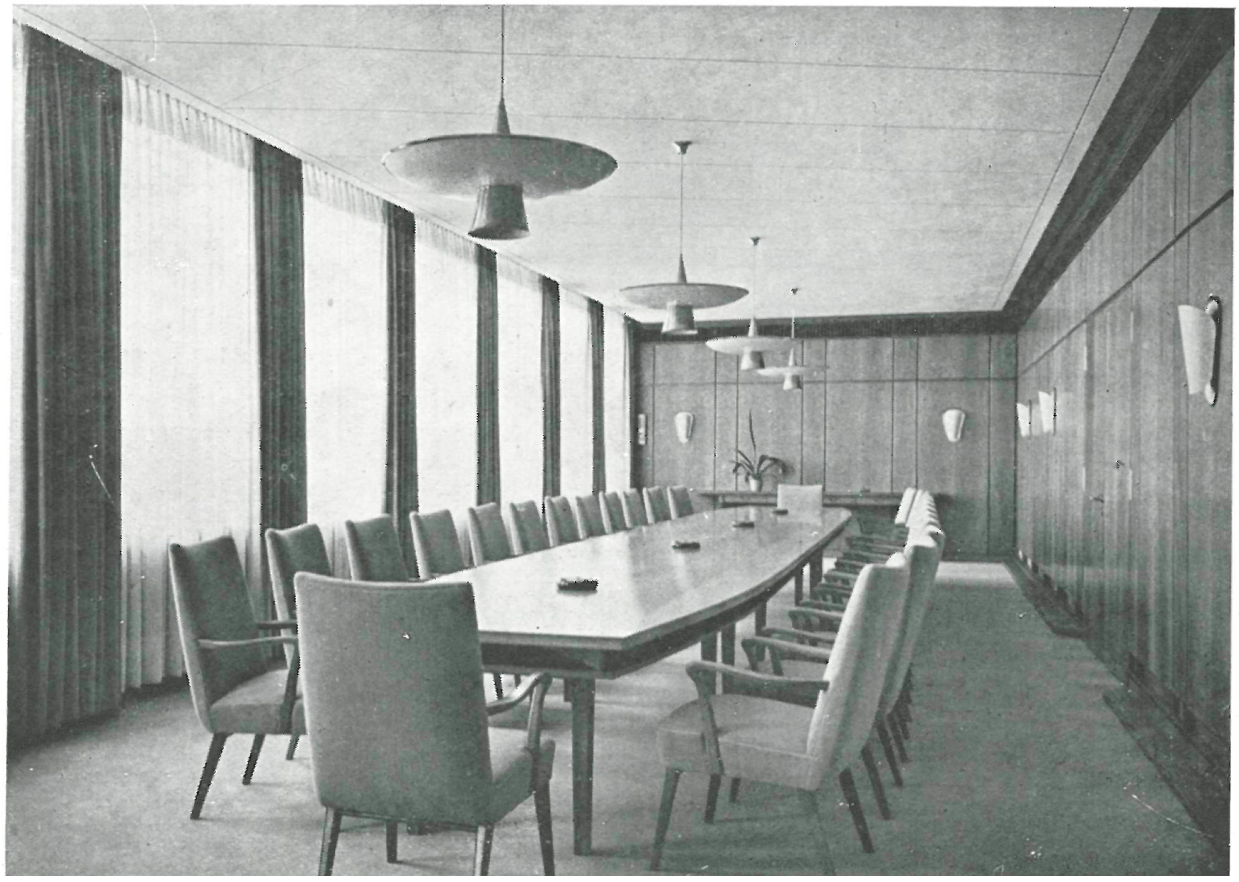

Salón de reuniones.

Fotos: HUGO SCHMOLZ 